\title{
Liminal but Competent: Latin American Migrant Children and School in Australia
}

\author{
María Florencia Amigó* \\ Macquarie University
}

\begin{abstract}
Indisputably school is the main institution that socialises migrant children into the culture of their new country. Through school they learn the new language and customs, which will enable them to become cultural brokers between the new cultural world and their families. During this process migrant children often transit a liminal terrain where their roles and identity become at the same time diverse and ambivalent. Despite the challenges involved these children often become experts in juggling different cultures, environments and expectations. This study explores the experiences of Latin American children and their families as they start primary school in Australia.
\end{abstract}

Keywords : migrant children, Hispanics, school, identity, liminality, Australia

Manuela is seven and is finishing year one. She was born in Spain of Peruvian parents, who migrated to Australia about three years ago. Manuela says she likes Spain best although she has almost no memories of it, and hasn't been back. She can speak some English and is doing fine at school, although she still has problems making friends. There are some other migrant children in her classroom but she is the only Spanish-speaking one. Now that she can speak English her mother says Manuela feels responsible for the wellbeing of her mother and grandmother who cannot speak the language. Manuela teaches her mother English, and helps her communicate whenever they go out together. She also makes sure that her two younger siblings who were born in Australia make an effort to talk to their grandmother in Spanish since she does not understand a single word of

* Corresponding Author: María Florencia Amigó, Honorary Research Associate, Children and Families Research Centre, Macquarie University, NSW, 2109, Australia. E-mail: maria. amigo@mq.edu.au
English. "She has a big sense of responsibility," her mother says. Manuela, as millions of other migrant children, mediates between different cultural environments. Her life unfolds between Spanish and English, between images of Spain, Peru and Australia, between her Latin American home and her Australian school, and she mediates between her Peruvian family and their -still unfamiliar-new homeland. This article will delve into the lives of recently arrived migrant Spanish speaking children and their families in Australia and the impact of starting school in the new country.

\section{Hispanics in Australia}

Spanish speaking migrants have been settling in Australia from the mid 1880s. López (2005) identifies four successive immigration waves: a first one consisting of Catalán migrants between the mid 1880s to 1933, a second larger one of Spanish migrants during the 60s and 70s, a third one from South America during the 70 s and 
early 80s, and a fourth one from Central America during the 80 s to early 90 s. The vast majority of these migrants came to Australia for either economic or political reasons. During the last decade, however, there has been a fifth wave of Spanish speaking migrants, predominantly from Latin America, who, in turn, are highly skilled and recount coming to Australia looking for a safer and more promising environment for themselves but especially for their children. They choose Australia for its skilled migration scheme that enables certain professionals within a specific age range, and with a good command of the English language to apply for permanent residency. Argentineans, Chileans, Colombians, Peruvians, and Venezuelans are the larger groups. Most of them are middle class, hold one or more university degrees, and had a good standard of living in their home countries.

First and second generation children of migrants comprise a large proportion of children in Australia. The 2006 Australian Household Census showed that $35 \%$ (or 1.5 million) of children in Australia live in migrant families, with about half of the total children living in migrant families being under 9 years of age, and within that group about half a million having been born overseas (Australian Bureau of Statistics, 2008). Figures from the New South Wales Department of Education and Training also reflect this large child migrant population. A 2010 report shows that almost 30\% of total enrolments in government schools were of students of language background other than English (Department of Education and Training, 2010). Children of Spanish speaking background were identified as the seventh largest group in New South Wales public schools. Despite Australia's history as a country of immigrants, the slow but steady increase in the new arrivals population each year, as well as its increasing diversity in terms of origin, socioeconomic background and settlement patterns, has meant that many schools that had remained mostly culturally homogenous, are experiencing significant cultural variety in their student population (Santoro, 2009). The literature that has focused on migration and acculturation -the cultural changes derived from intercultural contact-has paid less attention to women and children and family dynamics than it has to men (Sam, 2006). Also, although studies of cultural diversity in schools have been significant in the US and European contexts, they are still scarce in Australia (A few recent studies are Dockett \& Perry, 2005; Guo, 2005; Sanagavarapu \& Perry, 2005; Santoro, 2009). The literature on first generation migrant children's school experiences in the new country -in Australia and overseas - is limited, and tends to concentrate on refugees (e.g. Matthews, 2008). Finally, research that has looked specifically at the mutual influences that schools and first generation migrant children and their families exert on each other is rather incipient. Some works have marginally touched on these issues (Adams \& Kirova, 2007; Beraldi, 2006; Devine, 2007, 2009; Sanagavarapu, 2010) but the field is mostly unexplored and children's voices mostly absent. This article aims at contributing towards our understanding of children's experiences of migration in Australia by exploring the interplay between children's school and family lives, and the processes of adjustment involved.

\section{Conceptual Background}

There is an array of issues involved in the lives of migrant children as they start school in an unfamiliar culture. Primarily, children embark on a transition process through which they are progressively integrated to the new cultural world through school. This process is, however, by no means linear. They are continually referred back to the original cultural system prevailing in their families at home. The transition process seems to be embedded in sets of binary opposites children confront recurrently through their daily immersion in the domains of home and school. The data gathered for this study suggests that issues of approval/ disapproval, sameness/difference, inclusion/ exclusion, expansion/confinement permeate migrant children's lives and require adjustment strategies from them. A few analytical concepts 
have been coined to refer to these oscillating experiences of self and belonging in situations of migration, intercultural contact, or social change. The concept of "multiple belongings" (Vandenbroeck, 2001), has been particularly illuminating, as it sheds light on the dynamics of identity formation in mobile, globalised and post-traditionalists societies where individuals can adhere simultaneously to various reference groups, such as national, ethnic and language groups. The concept echoes the experiences implied in the idea of liminality (Turner, 1967), an anthropological notion that has been used to understand the psycho-social processes individuals undergo during change of status rituals in traditional societies. The concept of liminality refers to an undefined, ambiguous state of being, and has been used to shed light on situations of transition in social life. These theoretical conceptualisations have guided the interpretation of the data collected during this study.

\section{Method}

The data presented in this article is drawn from a small scale qualitative study that consisted of two stages, a first one based on an ethnographic approach, and a second one based on semi-structured interviews.

\section{Ethnographic Phase}

The purpose of including an ethnographic phase was to grasp "the native's point of view", or to understand what it is like to be a migrant family who faces the process of schooling in an unfamiliar setting. Ethnograpy is a qualitative methodological procedure where the researcher immerses herself in the everyday lives of the group she wants to study in order to get an insider's understanding. Ethnography entails thorough observation and detailed note taking of the everyday use of language, behaviours, and habits of a particular group, which are then analysed in order to develop conceptual interpretations of the social life of that group.
The interconnectedness and intimacy between researcher and subjects of study makes of ethnography a prime methodology for shedding light on different cultural and social worlds. The term "participant observation" captures the essence of the ethnographic approach.

The ethnographic phase lasted six months. During this period I endeavoured to meet Latin American families who had arrived in Australia within the last five years and had children aged five to eight attending primary school in the city of Sydney. I firstly contacted a Spanish speaking playgroup where mothers meet once a week to play with their pre-school aged children. In this playgroup I became acquainted with several migrant families from different Latin American countries (Argentina, Colombia, Mexico, Peru, and Venezuela). Four of these families showed interest in the research and fitted my selection criteria as they had recently arrived in the country and had school aged children aged five to eight. Playgroup mothers referred me to other settings where I could contact more recently arrived families that responded to the selection criteria. To be specific, I was invited to be a participant observer in migrant community centres, religious meetings, and private events such as birthday parties. My familiarity with Latin American cultural groups and my proficiency in Spanish were undoubtedly an advantage to make migrant families interested in the research. Each week during the first six months of data collection I attended the Spanish Playgroup which runs for two hours, and on average I participated in at least one other migrant reunion, whose length could range from between two to four hours. In these occasions I not only had the opportunity to meet newly arrived families, but also to interact with them informally, get a good understanding of their social realities and learn about their issues as new migrants in the country. I recorded all data gathered in these instances through thorough note taking during and after each meeting or event. 


\section{Interviews Phase}

Compared to formal interviews, an ethnographic approach allows for a more unstructured and relaxed collection of data, where the researcher interacts informally with the group and the information flows naturally, in part, perhaps, due to the avoidance of questionnaires and recorders. But the need for more specific information and the need to compare responses to the same questions made a second data collection phase involving formal interviews a necessary component.

During the ethnographic stage I recruited ten families from four different countries (Argentina, Mexico, Peru, and Venezuela) with children aged five to eight born overseas who did not speak English when starting school. Besides these criteria, the families were recruited because they agreed to participate in the second stage of the project and to be interviewed. Four of these families were recruited through the Spanish playgroup and the other six were families I had interacted with during other migrant gatherings (mentioned above).

As described in the introductory section these days about 80 per cent of migrants come to Australia through the skilled scheme, which implies that most new arrivals are professional middle class and used to a have a good standard of living in their countries of origin. It is worth noting too that the application to obtain a resident visa through this scheme is both expensive and demanding in terms of requisites. For example, in order to be eligible a skilled applicant needs a good level of English, professional studies and related work experience. This means that recent migrants who arrive under this scheme come from privileged backgrounds, a feature that was evident in the families recruited for this second phase.

As mentioned the second stage consisted of interviewing the parents and children in these families. Two different questionnaires were prepared for parents and children, and questions revolved around the experiences of starting school in a new country. The questionnaire for parents consisted of 12 semi-structured questions. Parents were asked, for example, about what were their expectations in relation to their children's education in the new country, how did the Australian education system differed from the one in their countries, and what were their pleasant surprises and disappointments in relation to school in Australia. Questions for children were short and straight forward. They were asked to answer ten questions on issues such as what were their memories when starting school in Australia, what are the best ways to make friends, or what had been the most difficult aspect of attending school in Australia. Interviews took place at each family's house and lasted between one hour and one hour and a half. I interviewed the parent or parents first (both parents were present in seven out of ten interviews, while only mothers were available for the other three), followed by a short interview to the child. In almost all instances (eight out of ten) the interviewed child preferred that one or both parents be present during the interview which meant the parents made comments to some of the child's responses (the opposite did not occur). All interviews were conducted in Spanish, digitally recorded and professionally transcribed.

\section{Data Analysis}

Data from the ethnographic phase (in the form of memos and written notes), and from the interviews phase were analysed qualitatively following the procedure suggested by grounded theory (Glaser \& Strauss, 1967). Grounded theory encourages the researcher to develop theory from the data by means of coding for recurrent themes that emerge from it. Based on her interpretation the investigator then groups themes into categories to eventually develop an explanation that fits the data and is relevant to the research question. The software NVIVO was used to organise and code all interviews, memos and notes taken. The results of this interpretative process are presented in this article.

It is important to make the note that when participants' direct quotes are included in the article these are translations from Spanish into 
English made by myself. I endeavoured to represent participants' voices as accurately as possible.

\section{Results}

\section{A New School in a New World}

Education for their children is one of the services migrants need the most, and most urgently. It is not unusual, therefore, for migrant children to come into contact with the receiving culture sooner and more intensely than their parents do. As Suárez Orozco and Suárez Orozco (2001) note, schools are where immigrant children first come into systematic contact with the new culture and they are probably the most important sites of cultural contact for them. Similarly, Laosa (1999, p. 372), claims that for ethnocultural and linguistic minority group children, schools are "the firstand perhaps the only—influential point of direct experience with a mainstream socializing insitution". And Luykx (2005) points at how sometimes the language and cultural distance between home and school make the school overshadow the family in its socialising role. The questions this study raises are therefore, how do migrant children -and their parentsexperience this abrupt and culturally different socialisation process of starting school in a new country? And, what are the outcomes and implications of this process for the children?

Studies that have focused on child migrants and school have been concerned almost exclusively with academic performance (Some exceptions are: Adams \& Kirova, 2007; Beraldi, 2006; Devine, 2009). In Australia, academic performance of first generation migrant children is not currently a matter of concern. Recent child migrants seem to perform well in school and there appears to be no significant connection between school achievement and being a child of a non-English speaking background. Katz and Redmond (2009) suggest that migrant parents' high educational attainment, due to Australia's current skilled migration policy, could partly explain their children's high academic achievement. The well documented emphasis migrant parents place on their children's education is most likely another reason. In the Australian context, a recent report suggests ethnic minority children themselves have big professional aspirations and want to succeed in school (Collins , Reid, Fabiansson, \& Healey, 2010). There is no published data on Latin American children school's performance in Australia, but this emerged as a recurrent topic during my conversation with parents, all of whom proudly mentioned that in spite of the difficulties surrounding the migratory experience their children's academic achievement had been remarkable, as the following quotes show:

The teachers have been telling me how surprised they are with Jacinta's progress and how she is excelling in school. In fact, even some Australian mothers who know her have told me that they can't understand how a migrant child can write and read even better than their own children (Consuelo, Mexican mother of six-year-old Jacinta).

In fact, he is the best in spelling in his class. And the teacher told us that for her it was remarkable that a child for whom the first language was not English could be so good at spelling. He also writes very well. His teacher is surprised by his good spelling and grammar (Leticia, Venezuelan mother of eight year-old Martin).

There are myriad factors that impact on migrant children's school performance, from specific familial conditions such as parents' socioeconomic background and education, to broader contextual factors such as the receiving country's attitude towards specific groups of migrants. As Zhou (1997) states for immigrants in the United States "In the long journey to becoming American, progress is largely contingent upon human and financial capital that their immigrant parents bring along, the social 
conditions from which their families exit as well as the context that receives them, and their cultural patterns -including values, family relations, and social ties-reconstructed in the process of adaptation” (p. 999). But even when first generation migrant children excel in school, as has been the case for many migrant groups in Australia and elsewhere (Duchesne, 1996; Katz \& Redmond, 2009; Ogbu \& Simons, 1998; Sam, 2006) reducing their lives to their academic performance as a measure of wellbeing is rather simplistic. Research on the school lives of migrant children has neglected the psychological burden that can accompany intercultural transitions (Laosa, 1999). Some small studies in the Australian context (MacNaughton, 2001; Mansouri \& Kamp, 2007; Mansouri \& Trembath, 2005; Santoro, 2009) show that prejudices and tensions in relation to migrant (first or subsequent generations) children in educational institutions are common among the children as well as between the teachers and the students. In fact, all interviewed parents were confident their children would do well academically. Conversely, their main preoccupation was whether their children would feel comfortable socially.

It has been argued that immigrants in Australia have a less satisfactory acculturation experience than in other countries, since despite Australia's multicultural policy, the emphasis is on assimilation rather than on integration (van Oudenhoven, 2006) ${ }^{1}$. That is to say, there tends to be an expectation that migrants should set aside their cultural and linguistic characteristics to be able to function fully in the host culture and adopt its core values. In his review of Australia's language and multicultural education policies since the 1970s, Liddicoat (2009, p. 201), put it succinctly:

1 Acculturation strategies are broadly grouped by Berry (1997) into: a) Assimilation strategies - where the acculturating group does not retain previous cultural identity, b) Separation strategies - the acculturating group holds on to previous culture and avoids contact with the new, c) Integration strategies - the acculturating group holds on to both the old and new cultures d) Marginalisation - the acculturating group finds it impossible to relate to either the old or new culture.
There is a different construction of interculturalism for members of minority groups in which maintenance of minority languages and cultures is conditional on adaptation to the majority culture and language. (...) Interculturality for the majority is a disposition towards other practices rather than an engagement with diversity, while for minorities it is seen as necessitating participation in the dominant culture, with the possibility of adding to or adapting linguistic and cultural repertoires to add economic value.

In the context of schools, Devine (2007, p. 150) refers to this lack of significant engagement with cultural diversity as "pragmatic multiculturalism", meaning that the school community acknowledges and respect the multiculturalism of the school but does not fully engage with it. Although she refers to Irish schools Devine's assessment echoes in Australia.

Learning English and making friends. Despite Australian schools' emphasis on multiculturalism and respect for diversity Latin American children's own experiences of feeling different are certainly more real than what their teachers and even parents perceive. For Martin, a Venezuelan boy, his own appraisal of his command of the English language provides an interesting example. His mother recounted:

Martin frequently tells me that he wants to learn more and more English, and then I tell him, "But my son, you already speak English and you speak English very well". And he replies, "Not yet, Mum. Not yet". Academically, his performance is excellent, but socially, he feels he is in disadvantage. He is having a difficult time. For his teacher, his English is more than fine, and he is doing really well. But when he plays with the other children, he misses out on a lot. That is because the adult world he is in contact with is in Spanish, unlike that of his classmates which is in English. Martin asked me to go to after 
school care so that he can learn more English and make friends.

As the case of Martin illustrates being able to speak the local language well is a major concern for migrant children. Related studies in the US have also pointed out at children's awareness of the power and status of the English language against their own. For example, Monzó and Rueda's (2009) study of Latin American school children in the US highlights the effort these children make to pass as fluent English speakers, an observation that is consistent with this study's findings.

Migrant children strive to speak the local language well, but also to make friends, as shown by Martin's example. These seem to be two intertwined and paramount aspects in Latin American children's school lives. Not surprisingly, the need to speak the language well and make friends has also been emphasised as crucial for other migrant children groups in the Australian context (e.g. Millar, 2011). My findings suggest that friendships are very important in migrant children's lives. As Vedder and Horenczyk(2006, p. 424) observe, migrant children "find friends as helpers in their struggle to find their position in the new social and cultural environment”. Devine (2009) also notices friendships are important sources of social capital for migrant children because they provide support, knowledge and access to networks.

The value of interpersonal relationships for collectivist cultures - such as Latin American societies who place emphasis on interdependence and reciprocal obligations - is crucial. So understandably, the topic of making friends at school was recurrent in both parents' and children's accounts. For instance Consuelo, a Mexican mother, told me that it was quite difficult for her daughter Jacinta to make friends at the beginning. One of her daughter's classmates used to give her a hard time, and she couldn't communicate with her. Jacinta used to tell her mother, "She talks to me in her language and I can't understand.” "And how do you reply to her?" the mother would ask, "Oh well, in
Spanish of course”. And Julio, a Peruvian father mentioned that for his son Francisco "the first friend was difficult to get”. Francisco remembers that he was teased severely in kindergarten, perhaps, he thinks, because he was coming from Peru, looked different and couldn't speak the language: "My number one friend is Michael. He was being very nice to me, when all my other friends were bullying me in kindergarten”. Finally, Antonieta, a Venezuelan mother recounted how her seven year-old son tells her he always has lunch alone and is too shy to ask anyone to play with him as he has to think too much before being able to speak in English.

For many Latin American migrant children, making friends from outside their language group is not easy. The data gathered for this study shows that language and cultural barriers can be major impediments for these children to feel confident in establishing relationships at the beginning. Making friends might involve minimising or hiding their cultural or ethnic identifiers such as special clothing, food, or their accent. As Devine discusses in her study of migrant children in Ireland, children did not tend to see their ethnic identities as positive attributes in facilitating their relationship with the local children. She also noticed that in order to make friends, migrant children participated in extracurricular activities that confirmed their commitment towards the local culture (p.526528). Devine's findings resonate in my study, where all parents and children interviewed suggested children's fervent commitment to the school's ethos and activities, as well as mentioned instances where children would refuse to eat their ethnic food at school, speak their language with their parents in front of friends, and try to talk, dress and behave like their non migrant peers.

It has been argued that for migrant children school provides a social field of knowledge and opportunities for participation in culturally valued activities (Devine, 2009), and the development of social networks for both child and parents which are essential to successful cultural adjustment (Christopoulou \& de Leeuw, 
2004). My data reflects these analyses: for Latin American children friendships provide the means for them to engage in the language and the codes of the receiving culture. When asked about what is it that they enjoy the most about school, all children interviewed mentioned their friends with whom they play sport, play in the playground, share food, and with whom they develop their shared Australian side of their identities.

\section{Migrant Children at a Crossroads of Expectations}

In her study of Bangladeshi children in English schools, Brooker (2005, p. 126) makes the point about the difficulty migrant children may face when starting school in an unfamiliar setting:

The direct clash of beliefs and practices between their parents and their teachers meant that they had double the work to do on starting school: not just becoming a pupil, but becoming a different kind of child from the one their family and community had created.

In fact, as Vedder and Horenczyk (2006, p. 420) point out schools are much more concerned with acculturating migrant children, or helping them adopt values and understandings of the receiving culture, rather than with enculturating them, or helping them understand their own cultural background. Discontinuities or inconsistencies between the home and school environments can be detrimental for the children academically, socially and emotionally (Dockett \& Perry, 2005). Although there would be "discontinuities of experience" between school and home settings for any child (Lam \& Pollard, 2006), for migrant children the disparities between both settings are more significant.

The tension between expectations from home and school was made evident in all interviews, where parents and children suggested that for children school was the space where the Australian values and identifiers need to be made explicit, while their ethnic ones made dormant. Parents, in particular, referred to habits and practices within the Australian school system that were very unfamiliar to them and were even a cause of concern. For example, all parents found the academic standards and the school discipline system of Australian schools much more lenient than expected, and tried to counterbalance this with stricter rules and extra homework at home. Also more trivial issues such as Australian schools' quick, informal and cold lunches sitting on the playground's floor are a shock to many parents who come from countries where lunch is the most important meal and where formalities sitting at the table need to be safeguarded, and still are in their new homeland. Likewise, they mentioned disapproval towards the carefree ways pupils tend to use their uniforms, use their hair or sit down during classroom time, and emphasised they did not want to see this behaviour in their own children, especially when at home.

Migrant parents therefore face the dilemma of how to manage - whether to accept, oppose or negotiate - their children's acculturation. As a migrant child progresses into school, traits of the new culture will quickly make a way into the child, overshadowing the culture taught at home (Qin, 2006). Although most parents mentioned they accept their child was becoming Australian in many aspects, all families clearly emphasised that it was paramount for them to reinforce their culture at home, and also to maintain the Spanish language. However, in spite of their efforts, most parents feared that their cultural influence over their children was limited, as Consuelo, a Mexican mother explained:

I think that if we reinforce our culture, our food, our festivals and all that belongs to us, to our children, they will incorporate it. But they will grow... Perhaps I am a bit afraid of the future when they will have new friends... and new ways...

The analysis of the experiences recounted by Latin American children and their parents suggests these children become entangled in a 
crossroads of expectations soon after they arrive in the country. Their teachers and parents expect them to do well in school and learn the language as well -and as fast-as possible, while their parents also aim at reinforcing their native culture and language. Their peers -responding to a particular socialisation system-pressure them to assimilate into the mainstream and to discard strong ethnic identifiers. Two socialisation systems interplay in the everyday lives of these children, the one that aims at transforming them into good Australian citizens operating at school, and the one that struggles to preserve their ethnic and cultural traits operating at home.

\section{Multiple Belongings}

What are the implications of this complex position that Latin American migrant children in Australia occupy? Identity obviously comes into question. How do young children in the process of making sense of and moulding their identities go about juggling cultural traits and responding to the expectations of two different cultural systems (their families and their schools)? Whereas newly arrived adult migrants who come with a defined cultural identity might not be immediately urged to interact with members of the host country and use the new language on a daily and systematic basis, school children are. And therefore for them, the acculturation process can be more confronting than it is for their migrant parents, at least during the period immediately after arriving. Besides experiencing two sudden changes of status as they start school - they become Australian "pupils" and "migrant students" -, and the sudden immersion into an unfamiliar cultural and social world, back home they encounter a continuation of the social and cultural life they left behind in their home countries. What impact does this dual process have on migrant children's evolving identities?

During interviews both parents and children alluded to situations where children would dress, behave, eat and speak in particular ways depending on the cultural context, suggesting strong contrasts in how children act out their identity. One could argue that most of us unfold different dimensions of our identities depending on the context, however for the children in the study reported in this article, the cultural clashes between different contexts and the concomitant behaviour that is expected from them is sharper.

Children's relation with food and language can be cases in point of how migrant children may use such cultural resources as an expression of their newly forged identities. Almost all children and parents referred to children's preference of taking Australian food for their lunch break in school, while refusing to take their country's typical food which they would happily eat at home. Food can be used as a symbolic resource to negotiate group boundaries in peer interaction (Nukaga, 2008). When I asked Marta, the Argentinean woman, in which aspects she thought her daughter Rocio was more Australian than Argentinean, she immediately mentioned food:

The most Australian feature that I notice in Rocio is in her food habits. She is very Australian in that sense. She eats carrot sticks and wants vegemite sandwiches every day to take to school. It surprises me. In that respect she is more Australian than the Australian people.

Similary language, as a powerful symbol of national and ethnic identity (Spolsky, 1999, p. 181 ), can be an indicator of migrant children's multiple belongings. Five of the children interviewed expressed a reluctance to speak Spanish outside their homes, and mentioned being embarrassed when their parents spoke Spanish in public situations. They were, however, willing to use their native language at home with their families. Even for some, the way they combine both languages in everyday speech could be interpreted as the result of the ambivalent social space in which their lives unfold. For example, during the interview, Manuela, the Peruvian girl did not say any sentence fully in Spanish or in English. Talking about school rules, she said, 
Asi, en kindergarten cada rato necesita sit in line, $y$ ahora nosotros sit in that line, in kindergarten necesita sit in that line. Ahora es that way. Y necesita se sit in the sun y que no tiene gorro te vas hacia el calor, gorro, tu vas a sit in the shade, no playing time. $\mathrm{Y}$ también otro rule, $\mathrm{y}$ también otro rule. Hay muchos rules en el colegio... Hay muchos rules en el colegio. Hands off and don't talk when the teacher is talking. Yo no dije que puedes hablar cuando la teacher está talking! Asi y también cuando tu no estás watching, you'll never learn again. (English words are underlined)

Studies of code-switching, which linguists describe as alternation in the use of two languages between two bilingual speakers, have described it as a strategy to enhance the communication between the speakers, or as a symptom of language deficiency (Cheng \& Butler, 1989). However my analysis suggests that code switching in children is also an indication of the fluctuating cultural and linguistic spaces they engage with on a daily basis.

Schools and peer pressure are strong influencers of children's identity. For Latin American migrant children in Australia, however, this process is often times counterbalanced at home with differing expectations. These children need therefore to find ways of responding to both systems while developing their sense of self and belonging at the same time. According to Santoro the identity migrant children construct is "a newly forged identity rather than an identity that is an amalgam of the distinctive characteristics of a number of cultures" (Santoro, 2009, p. 38). Similarly, Eskner and Orellana (2005) mention how the practices of immigrants can become permanent new social practices that lead to new cultural forms and identities. In fact, most parents interviewed for this study, saw their children and their practices in this way, neither Latin American, nor Australian, nor a combination of both. "That's how she is," said
Marta, the Argentinian mother when referring to her daughter. "I can't think 'she is more Australian, or she is very Argentinian'. It's just her".

Some recent studies have pointed out that despite their oscillating identity faces and roles, migrant children do not necessarily show signs of being confused, dislocated or out of context (e.g. Bak \& von Bromssen, 2010; Eskner \& Orellana, 2005), but rather seem to "embrace quite harmoniously their different belongings and be inspired by the wider world" (Bak \& von Bromssen, 2010, p. 121). Despite some initial difficult times the children in the study also respond to this assessment. Their multiple belongings and liminal position may not only make them more culturally aware and strategic, but may also circumstantially empower them.

\section{"Betwixt and Between”: Migrant Children as Mediators}

(The liminal state is) ambiguous, neither here nor there, betwixt and between all fixed points of classification (Turner, 2002 p. 96)

Turner's description of the liminal phase has been borrowed by many to illustrate situations of transition in social life. Although referring specifically to rites of passage in which a change of status is involved, many of the characteristics of the liminal phase described by Turner resonate when exploring the lives of child migrants and the impact of school during their first years in the new country. Issues of ambiguity, change of status, vulnerability, transition between different contexts, lack of membership in established categories -typical of the liminal phase - are recognizable in the lives of migrants.

Eksner and Orellana (2005) have, however, warned us about the shortcomings involved in applying the term unconditionally to understand migrant lives. These authors find the concept inappropriate to refer to migrants' lives because it is a) temporarily bound, referring to a period of time that has a clear beginning and end, b) 
does not account for the complex power issues interplaying in migrants' lives, and c) does not allow for the "multiple liminalities" as the complex system of memberships, exclusions and transitional phases present in migrants' experiences. While I acknowledge these limitations, and do not attempt to apply the term unconditionally, I believe the concept of liminality is illuminating when exploring the lives of recently arrived migrant school children who find themselves in situations of ambiguity and who may embrace multiple identities or belongings. In particular, its associated notion of "betwixt and between" is even more elucidating when exploring the mediating roles many of these children perform for their parents and siblings, teachers and peers. As they start operating 'betwixt and between' two cultures, two languages and two socialising systemstheir families and the school — their situation of liminality makes them at the same time competent individuals who are able to navigate the cultural domains of two systems. The accrual of experiences, skills, and knowledges (including of course language) that Latin American children in Australia acquire through school enables them to become cultural mediators, often undertaking a major role in socialising their parents into the new language and culture.

References to children acting as mediators were frequent during interviews. Parents gave numerous examples of their children assisting with language, but also helping them understand value systems in Australian society. Similarly, children themselves gave us examples of how they would help their parents and grandparents in everyday situations, and even translate to teachers and peers when needed. Consuelo, the Mexican woman, explained to me she is still having a very hard time trying to communicate in English, and her daughter is of invaluable assistance:

Jacinta helps me. She helps me a lot when we are out and about. I ask her all the time, "How do I say this or that?" And she tells me "Mum, you say it this way, put your tongue like this to pronounce it well...” And now that we are on holidays I ask her to talk to me in English so that I learn, but we start in English and then I go back to Spanish and she tells me "Come on Mum, didn’t we agree we were going to practise English?”

Mariela, an Argentinian six-year-old, recounted how she helps a newly arrived Spanish speaker in her classroom:

There is a new child at school who speaks Spanish and I am helping him so that he can understand what the teacher says. They put him in my class because I speak Spanish. The teacher wants me to help him too. So for example, if the teacher says "draw a flower", I tell him what she is saying so he can do it too.

And Antonia, a Peruvian mother gave an example of how her seven-year-old daughter and ten-year-old son introduce her to the Australian ethos:

In Peru it's OK to identify people by their ethnicity or religion. You can say "that one is a black person, that one is a Chinese, that one is a Jew". But my daughter and son get really upset if I refer to anyone in that way. When I told my daughter once "so you have a Chinese friend", she got really upset and said: "That's being racist. My friend has a name. In Australia we are all the same and you call people by their names". This is what they teach them at school and I am learning from them.

Issues of role reversal are worthy of analysis here, where sometimes Latin American migrant children, who usually master the English language after two years, not only become their parents' language teachers, but also the ones who explain the new country's culture to them, or even feel responsible for their wellbeing. Several works have shown how children 
become their parents' cultural mediators, translators, and carers in some situations (Christopoulou \& de Leeuw, 2004; De Block \& Buckingham, 2007; Orellana, Dorner, \& Pulido, 2003; Smokowski, Rose, \& Bacallao, 2008). Children's new roles have the potential to interfere with the socialising role of their home environments by introducing more culturally and educationally valued practices (Christopoulou \& de Leeuw, 2004), and often present a disruption of the Western adult-child relation model where adults guide and protect their children and might generate anxiety in parents (Eskner \& Orellana, 2005). However, the core argument of this paper is that children's crucial roles as language and cultural brokers offer the potential to empower them and to counterbalance the vulnerability they are subjected to in their condition of liminal subjects. As Bak and Von Bromseen (2010) have argued, migrant children have "diasporic consciousness", which entails "diasporic practices" and "multiple social identities" makes them competent migrant children rather than incompetent ones (until today, the prevalent perception of ethnic minority children in school settings).

\section{Conclusion}

Latin American migrant children in Australia transit between cultural worlds on a daily basishence their liminality-often experiencing anxiety both at home and in school. Through school they incorporate the norms, codes, and practices of the new culture -usually with difficulties-which they will then translate to their parents, grandparents and sometimes even younger siblings. But while the school aims at standardising diversity at least to certain degree-one of the tacit purposes of public education - the family attempts to maintain a strong sense of connection to an ethnic, linguistic and cultural identity. Therefore this research suggests that Latin American children in Australia -and this may be true for many migrant children in diverse contexts-are often betwixt and between what the state and community desire from them and what their parents expect from them and teach them.

While challenging, this position they occupy is enabling -rather than disabling. The lives of migrant children have often been conceived within a "deficit model" that emphasizes what these children cannot do (speak, understand, adjust) instead on focusing not only on what they can do, but also on how they take advantage of their liminal position to act strategically and mould their lives in ways that benefit them.

In the end, they become the link between the old world and the new one. As Orellana et al. (2001) say, children in migrant families help constitute and reconfigure transnational social fields and transnational practices that shape particular childhoods.

Despite the small-scale nature of this study, and the specificity of the population studied the analysis of the data gathered has shed light on the complexity of issues newly arrived migrant children in Australia and their families may experience. Recent waves of migrants to Australia, as this study shows, differ significantly from previous ones in that they are highly educated and often determined to make their language and culture prevail. This can have policy implications: schools could seize this opportunity and take advantage of the multiple belongings of these children not by merely respecting diversity, but by engaging with it and embodying it through their ethos and practices. Migrant children carry with them the invaluable ability to connect different cultural worlds, a potential that needs to be acknowledged and utilized.

\section{References}

Australian Bureau of Statistics. (2008). The people of Australia: Statistics from the 2006 census. Canberra: Department of Immigration and Citizenship. Retrieved from www.immi. gov.au/media/publications/statistics/comm.../s ource.htm. 
Adams, L., \& Kirova, A. (Eds.). (2007). Global migration and education: Schools, children and families. New Jersey, London: Lawrence Erlbaum Associates

Bak, M., \& von Bromssen, K. (2010). Interrogating childhood and diaspora through the voices of children in Sweden. Childhood, 17(1), 113-128.

Beraldi, C. (Ed.). (2006). Education and intercultural narratives in multicultural classrooms. Rome: Offizina Edizioni.

Berry, J. W. (1997). Immigration, acculturation, and adaptation. Applied Psychology, 46(1), 534.

Brooker, L. (2005). Learning to be a child: Cultural diversity and early years ideology. In N. Yelland (Ed.), Critical issues in early childhood education (pp.115-130). Maidenhead: Open University Press.

Cheng, L., \& Butler, K. (1989). Code switching: A natural phenomenon versus language deficiency. World Englishes, 8(3), 292-309.

Christopoulou, N., \& de Leeuw, S. (2004). Home is where the heart is: Family relations of migrant children in media clubs in six European countries. Children in communication about migration (CHICAM). Retrieved from www.chicam.org/reports/ index.html

Collins , J., Reid, C., Fabiansson, C., \& Healey, L. (2010). Tapping the pulse of youth in cosmopolitan South-Western and Western Sydney. Retrieved from www.immi.gov.au/ media/publications/.../tapping-pulse-youth.pdf

De Block, L., \& Buckingham, D. (2007). Global children, global media: Migration, media and childhood. Basingstoke: Palgrave Macmillan.

Department of Education and Training (DET). (2010). Students from language backgrounds other than English. Sydney: New South Wales (NSW) Department of Education and Training. Retrieved from https://www.det. nsw.edu.au/about-us/.../key-statistics-andreports.

Devine, D. (2007). Immigration and the enlargement of children's social space in school. In H. Zeiher, D. Devine, A. T. Kjørholt \& H. Strandell (Eds.), Flexible childhood? Exploring children's welfare in time and space. Odense: University Press of Southern Denmark.

Devine, D. (2009). Mobilising capitals? Migrant children's negotiation of their everyday lives in school. British Journal of Sociology of Education, 30(5), 521-535.

Dockett, S., \& Perry, B. (2005). Starting school in Australia is 'a bit safer, a lot easier and more relaxing': Issues for families and children from culturally and linguistically diverse backgrounds. Early Years: An International Journal of Research and Development, 25(3), 271-281.

Duchesne, S. (1996). Parental beliefs and behaviour in relation to schooling. (Ph.D. ), Macquarie University, Sydney.

Eskner, J., \& Orellana, M. (2005). Liminality as linguistic process: Immigrant youth and experiences of language in Germany and the United States. In J. Knörr \& A. Nunes (Eds.), Childhood and migration: From experience to agency. Bielefeld \& Somerset, NJ: Transcript and Transaction Publishers

Glaser, B., \& Strauss, A. (1967). The discovery of grounded theory: Strategies for qualitative research. Chicago: Aldine Transaction.

Guo, K. (2005). Developing in a new languagespeaking setting. Australian Journal of Early Childhood, 30(3), 39-44.

Katz, I., \& Redmond, G. (2009). Review of the circumstances among children in immigrant families in Australia. Innocenti Working Paper (Vol. 2009-12). Florence: UNICEF Innocenti Research Centre.

Lam, M. S., \& Pollard, A. (2006). A conceptual framework for understanding children as agents in the transition from home to kindergarten. Early Years: Journal of International Research \& Development, 26(2), 123-141.

Laosa, L. M. (1999). Intercultural transitions in human development and education. Journal of Applied Developmental Psychology, 20(3), 355-406.

Liddicoat, A. J. (2009). Evolving ideologies of the intercultural in Australian multicultural and language education policy. Journal of 
Multilingual and Multicultural Development, 30(3), 189 - 203.

López, R. (2005). Hispanics in Australia: An imagined community of communities. Journal of Iberian and Latin American Studies, 11(1), 103-110.

Luykx, A. (2005). Children as socializing agents: Family language policy in situations of language shift. Paper presented at the 4th International Symposium on Bilingualism.

MacNaughton, G. (2001). Silences and subtexts of immigrant and nonimmigrant children. Childhood Education, 78(1), 30-36.

Mansouri, F., \& Kamp, A. (2007). Structural deficiency or cultural racism: The educational and social experiences of Arab-Australian youth. Australian Journal of Social Issues, 42(1), 87-102.

Mansouri, F., \& Trembath, A. (2005). Multicultural education and racism: The case of Arab-Australian studentsin contemporary Australia. International Education Journal, 6(4), 516-529.

Matthews, J. (2008). Schooling and settlement: Refugee education in Australia. International Studies in Sociology of Education, 18(1), 3145.

Millar, N. (2011). Korean children's cultural adjustment during transition to the early years of school in Australia. Australasian Journal of Early Childhood, 36(3), 10-18.

Monzó, L. D., \& Rueda, R. (2009). Passing for English fluent: Latino immigrant children masking language proficiency. Anthropology \& Education Quarterly, 40(1), 20-40.

Nukaga, M. (2008). The underlife of kids' school lunchtime negotiating ethnic boundaries and identity in food exchange. Journal of Contemporary Ethnography 37(3), 342-380.

Ogbu, J. U., \& Simons, H. D. (1998). Voluntary and involuntary minorities: A culturalecological theory of school performance with some implications for education. Anthropology and Education Quarterly, 29(2), 155-188.

Orellana, M., Dorner, L., \& Pulido, L. (2003). Accessing assets: Immigrant youth's work as family translators or "para-phrasers". Social Problems, 50(4), 505-524.

Orellana, M. F., Thorne, B., Chee, A., \& Lam, W. S. E. (2001). Transnational childhoods: The participation of children in processes of family migration. Social Problems, 48(4), 572-591.

Qin, D. B. (2006). "Our child doesn't talk to us anymore": Alienation in immigrant Chinese families. Anthropology and Education Quarterly, 37(2), 162-179.

Sam, D. (2006). Acculturation of immigrant children and women. In D. Sam \& J. Berry (Eds.), The Cambridge handbook of acculturation psychology. Cambridge Cambridge University Press.

Sanagavarapu, P. (2010). What does cultural globalisation mean for parenting in immigrant families in the 21st century? Australasian Journal of Early Childhood, 35(2), 36-42

Sanagavarapu, P., \& Perry, B. (2005). Concerns and expectations of Bangladeshi parents as their children start school. Australian Journal of Early Childhood, 30(3), 45-57.

Santoro, N. (2009). Teaching in culturally diverse contexts: What knowledge about 'self' and 'others' do teachers need? Journal of Education for Teaching, 35(1), 33-45.

Smokowski, P. R., Rose, R., \& Bacallao, M. L. (2008). Acculturation and Latino family processes: How cultural involvement, biculturalism, and acculturation gaps influence family dynamics. Family Relations, 57(3), 295-308.

Spolsky, B. (1999). Second-language learning. In J. Fishman (Ed.), Handbook of language and ethnic identity (pp. 181-192). Oxford: Oxford University Press.

Department of Education and Training (DET). (2010). Students from language backgrounds other than English. Sydney: New South Wales (NSW) Department of Education and Training. Retrieved from https://www.det. nsw.edu.au/about-us/.../key-statistics-andreports.

Suárez-Orozco, C., \& Suárez-Orozco, M. (2001). Children of immigration. Cambridge, MA: Harvard University Press. 
Turner, V. (1967). The forest of symbols: Aspects of Ndembu ritual. Ithaca, N.Y.: Cornell University Press.

Turner, V. (2002). Passages, margins and poverty: Religious symbols of communitas. In J. Vincent (Ed.), The anthropology of politics: A reader in ethnography, theory and critique (pp. 96-101). Oxford: Blackwell Publishing.

van Oudenhoven, J. P. (2006). Immigrants. In D. Sam \& J. Berry (Eds.), The Cambridge handbook of acculturation psychology. Cambridge: Cambridge University Press.

Vandenbroeck, M. (2001). The view of the jeti. The Hague: Bernard Van Leer Foundation.
Vedder, P., \& Horenczyk, G. (2006). Acculturation and the school. In D. Sam \& J. S. Berry (Eds.), The Cambridge Handbook of Acculturation Psychology. Cambridge: Cambridge University Press.

Zhou, M. (1997). Segmented assimilation: Issues, controversies, and recent research on the new second generation. International Migration Review, 31, 975-1008.

Received November 1, 2011

Revision Received December 18, 2011

Accepted January 20, 2012 